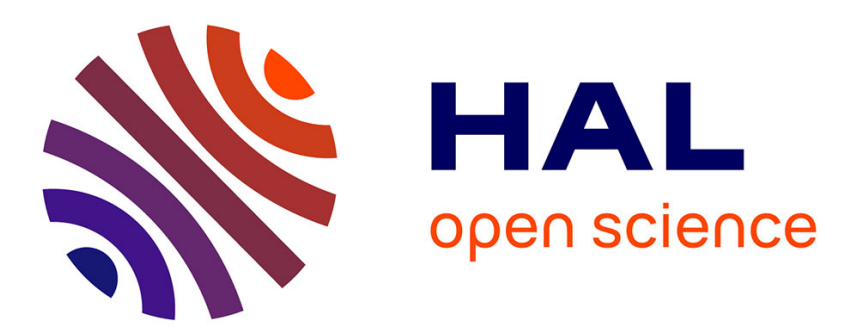

\title{
Polymer additive manufacturing of ABS structure: Influence of printing direction on mechanical properties
}

Hossein Ramezani Dana, Fabrice Barbe, Laurent Delbreilh, Mouldi Ben Azzouna, Alain Guillet, Thomas Breteau

\section{- To cite this version:}

Hossein Ramezani Dana, Fabrice Barbe, Laurent Delbreilh, Mouldi Ben Azzouna, Alain Guillet, et al. Polymer additive manufacturing of ABS structure: Influence of printing direction on mechanical properties. Journal of Manufacturing Processes, 2019, 44, pp.288-298. 10.1016/j.jmapro.2019.06.015 . hal-02327086

\section{HAL Id: hal-02327086 \\ https://hal.science/hal-02327086}

Submitted on 1 Sep 2020

HAL is a multi-disciplinary open access archive for the deposit and dissemination of scientific research documents, whether they are published or not. The documents may come from teaching and research institutions in France or abroad, or from public or private research centers.
L'archive ouverte pluridisciplinaire $\mathbf{H A L}$, est destinée au dépôt et à la diffusion de documents scientifiques de niveau recherche, publiés ou non, émanant des établissements d'enseignement et de recherche français ou étrangers, des laboratoires publics ou privés. 


\title{
Polymer Additive Manufacturing of ABS Structure: Influence of Printing Direction on Mechanical Properties
}

\author{
H. Ramezani Dana *, F. Barbe, L. Delbreilh, M. Ben Azzouna, A. Guillet, T. \\ Breteau
}

Normandie Univ, INSA Rouen, UNIROUEN, CNRS, GPM, 76000 Rouen, France

\begin{abstract}
:
The present study relates to Polymers Additive Manufacturing (PAM) traditionally used for rapid prototyping operations. The use of PAM components as functional parts is still marginal compared to injection molded components. This is due to the uncertainty on their mechanical properties and to the present knowledge on PAM products. A new additive manufacturing technology has been integrated in the Freeformer-Arburg machine. It was inspired by injection molding technology and creates plastic parts using layers built up from tiny droplets of polymer. In this work, the mechanical characterization of thermoplastic polymer parts obtained by Arburg Plastic Freeforming (APF) is studied. Additionally the mechanical properties of polymer specimens obtained by injection molding as a conventional process are studied in order to evaluate the influence of the manufacturing process on the parts mechanical behavior. The tensile mechanical properties are evaluated by varying some manufacturing parameters, such as the printing path. Microstructural analyses have been performed to better understand the relationship between the manufacturing process and the final mechanical properties.
\end{abstract}

Keywords: Polymer additive manufacturing (PAM), Acrylonitrile Butadiene Styrene (ABS), Mechanical characterization, Printing orientation

Corresponding author. Tel.: +33612808764 .

E-mail addresses: hossein.ramezani-dana@insa-rouen.fr, hossein.ramezani_dana@yahoo.com.

\section{Introduction}

Polymer additive manufacturing (PAM) or 3D polymer printing is a process that has attracted growing attention over the past three decades, initially for rapid prototyping operations. This process has expanded over the past few years due to the numerous advantages it offers, particularly in terms of the geometrical complexity of the produced parts. In a manufacturing process, this makes it possible to reduce the number of components and assemblies, as well as to produce parts with geometries that would otherwise be difficult [1] or impossible to make using conventional injection molding. In a manufacturing process, this process opens up new routes for the design of materials and structures, and makes coupling with optimization tools very relevant. Understanding these processes is therefore of paramount importance when it 
comes to producing functional parts [2], [3]. It is essential to master the quality of the manufactured parts and to understand the impact of the process on their final properties. A variety of additive manufacturing techniques exist today. Amongst these techniques, Polyjet [4], [5], [6], [7] stereolithography [8], [9], [10], selective laser sintering [11], [12], [13], [14] and Fused deposition modeling [15], [16] are the most frequently cited. Recently, a new technology of additive manufacturing has been integrated in the Freeformer-Arburg machine [17]. It consists in building the part by depositing tiny droplets of extruded polymer. Commonly known as "Arburg Plastic Freeforming" (APF), this technique is mainly oriented in research and development, and targets various applications (e.g. the medical and automotive sectors). Only few studies dealing with this technique have been presented in the literature. Most of the references concerning deposition of extruded polymers concern the FDM technique.

The mechanical properties of polymer parts obtained by additive manufacturing have been studied by numerous authors [18], [19], [20], [21], [22], [23], [24]. Printing parameters such as printing direction, layer thickness, infill degree, and feed rate, amongst others, have a considerable effect on the quality and performance of PAM built parts [25], [26], [27], [28], [29], [30], [31]. The influence of the printing path on the mechanical properties of the part realized by the PAM process have been extensively studied [32], [31], [33], [20], [25], [34], [18]. Ahn et al. [31] found that the raster orientation greatly affects the tensile strength of ABS part but the printed beads width and the bed temperature have little effect on it. Domingo-Espin et al. [20] have discussed that in addition to the printing orientation, other parameters such as nozzle size, thickness and position can significantly affect the mechanical properties of the polycarbonate (PC) piece produced by additive manufacturing.

Likewise the influence of the layer thickness on the mechanical properties has been discussed in different works [32],[35], [31], [33], [26], [31], [25]. Rankouhi et al. [25] have studied the effects of layer thickness and raster orientation on the mechanical properties of 3D printed ABS specimens by running an extensive experimental investigation in order to address the controversy in the literature regarding the effects of printed layer thickness. Their tensile test results, along with statistical analyses of the data, clearly suggest that specimens with $0.2 \mathrm{~mm}$ layer thickness are stronger than specimens with $0.4 \mathrm{~mm}$ layer thickness and that layer thickness and raster orientation both have a significant effect on the mechanical properties of printed specimens. Some authors [32], [34] have mentioned the impact of infill degree on the mechanical behaviors of produced components.

Caneiro et al. [32] have shown that the layer thickness has little influence on the mechanical performance of polypropylene (PP) specimens. By contrast, the infill degree does have a dramatic and linear effect on the specimens mechanical properties. Some studies [33], [26] have taken into account the influence of feed rate on the mechanical behavior of resulting components. Anitha et al. [26] have noted that the effect of layer thickness on the surface roughness of the components produced via the PAM process is significant. By contrast, the effect of feed rate on the specimen quality is insignificant. Chacon et al. [33] found that the effect of the feed rate on the tensile and flexural strength of PLA specimens manufactured using the PAM process was of slight significance.

Melenka et al. [3] have applied a design of experiments (DOE) test protocol to determine the effect of the layer height, infill degree and print orientation variables on the mechanical properties of PLA printed parts. The classical laminate plate theory has been used to compare results from the DOE experiments with theoretically predicted elastic moduli for tensile specimens. The DOE study has shown that infill has a significant effect on the material 
properties of the PLA printed parts, whereas layer thickness and print orientation were not shown to affect significantly the specimens properties.

Other studies [36] have characterized the influence of the printing rate on the mechanical properties of printed ABS specimens. They have revealed that faster printing speeds lead to larger porosities and residual stresses, as well as greater shrinkage after specimen thermal treatment. Furthermore, raster angle has a greater influence on specimen shrinkage and porosity compared to printing speed. ABS specimens with raster angle of $45^{\circ}-45^{\circ}$ show less shrinkage and porosity compared to those with a raster angle of $0^{\circ}$ and $0^{\circ} / 90^{\circ}$. The influence of porosity in 3D printed ABS specimen obtained by FDM process is considered by Guessasma et al. [37]. The authors have employed X-ray microtomography to characterize the 3D microstructures of the specimens printed in different orientations. Their study confirms that printing with directions alternating from $-45^{\circ}$ to $+45^{\circ}$ from a layer to the next represent the lowest pore connectivity. Though the structures revealing the largest pore size are those corresponding to specimens with a unidirectional printing.

Recently, the effects of environmental conditions, ageing and build orientation on the mechanical properties of specimens manufactured via the PAM process have been evaluated [38]. Puebla et al. [39] have indicated that the effects of aging and pre-conditioning on the mechanical properties of the Stereolithography (SLA) compounds are considerable. Kim et al. [38] have noted that the tensile strength and Young's modulus of ABS specimens elaborated via FDM process decrease linearly as temperature and water absorption rates increase.

The majority of these studies are relying on the FDM technique and the only one relating to APF, as far as the authors know, is [40]. Guessasma et al. [40] have studied the advantage and constraints of multi-material three-dimensional (3D) printed pieces. The authors quantified the quality of the interface between the two thermoplastics via tensile test assisted with digital image correlation. They found that the quality of the interface is decisive for improving the final performance of multi-material structure. Table 1 groups several studies on the processproperties relationships, according to the considered material.

\begin{tabular}{|c|c|c|c|c|c|}
\hline \multirow{2}{*}{ Parameter } & \multicolumn{5}{|c|}{ Material } \\
\cline { 2 - 5 } & PLA & ABS & PP & PC & PEEK \\
\hline Printing path & {$[18],[19],[22]$} & {$[18],[19],[21],[24],[25]$,} & {$[32]$} & {$[20]$} & {$[21]$} \\
& & {$[27],[28],[29],[31],[38]$} & & & \\
\hline Layers thickness & {$[19],[22],[3]$,} & {$[19],[21],[25],[28]$} & {$[32]$} & & {$[21]$} \\
\hline Infill degree & {$[19],[22],[33],[34]$} & {$[19]$} & {$[32]$} & & \\
\hline Feed rate & {$[33],[3]$} & {$[25],[36]$} & & & \\
\hline
\end{tabular}

Table 1: A list of studies on the effect of printing parameters in PAM.

This study aims at evaluating the mechanical properties of ABS parts elaborated with the APF technique. The characterization of the ABS parts was carried out by varying the deposition trajectory of the polymer layers. The tensile mechanical properties of the parts obtained by APF are compared with those obtained by injection molding, considered as a reference technique. The mechanical characterization of the consolidated specimens was carried out using quasi-static tensile tests. Finally, X-ray microtomography analyses was carried out in order to evaluate the morphology of the printed parts according to the processing parameters. 


\section{Description of the manufacturing process}

\subsection{Arburg Plastic Freeforming (APF) process}

The APF process is derived from injection molding: it consists in extruding thermoplastic granulates with a screw which drives the material from the hopper to the injection nozzle (figure 1). The pellets are gradually heated until they reach the peak temperature at the end of the screw. The fusion of granules results from the combined action of the thermal energy used to heat the sheath and the mechanical energy resulting from the viscous friction generated by the rotation of the screw. A stationary discharge unit with a specific nozzle deposits tiny plastic droplets layer-by-layer onto a part carrier using high-frequency piezoelectric technology. The layer thickness, related directly to the diameter of the obtained droplets, also depends on the diameter of the nozzle.

In this study, a nozzle with a diameter of $0.15 \mathrm{~mm}$ was used. The deposited layers have a thickness of $0.21 \mathrm{~mm}$ by adjusting the manufacturing parameters. The procedure takes into account the diameter of the droplets to define the infill degree selected beforehand (less than or equal to $100 \%)$.

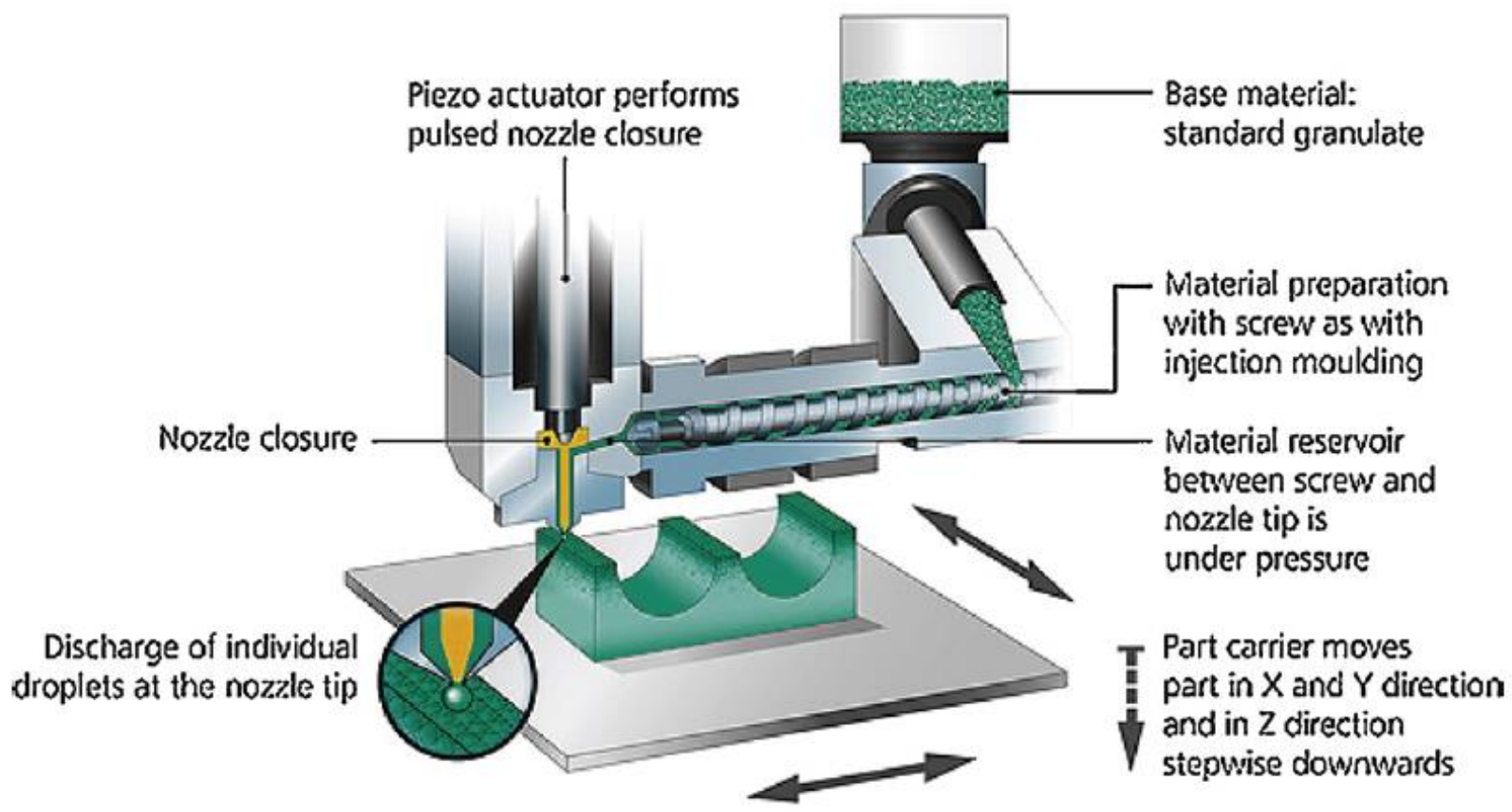

Figure 1: Diagram of the Arburg Plastic Freeforming process (courtesy of ARBURG).

\subsection{Injection molding technology}

In order to evaluate the effect of processing on the mechanical properties, a comparative analysis of the tensile properties of specimens elaborated either by APF or by injection molding is proposed. Tensile specimens were fabricated by injection molding in order to determine the reference tensile properties of the ABS material under concern in this study. This process yields much more isotropic parts than the APF process. Using this process, it is possible to produce pieces with complex shapes from thermoplastic pellets in a single operation. The nozzle temperature of the injection press was $250{ }^{\circ} \mathrm{C}$, the mold preheat temperature was $120{ }^{\circ} \mathrm{C}$, the clamping force was $62.5 \mathrm{kN}$, and the injection pressure was $265 \mathrm{MPa}$. 
The dimensions of the mold cavity for the tensile specimen were the same as those of the APF printed specimen. The shrinkage of the molded ABS was observed to be negligible. All the injection molding specimens tested in this study have been manufactured using a Babyplast ${ }^{\circledR}$ 6/6 injection molding machine.

\section{Experimental methodology}

In this paragraph, the material, equipment and conditions used in the elaboration and mechanical characterization of the specimens is described in details.

\subsection{Material and specimens geometry}

In this study the commercial Terluran GP-35 ABS pellets manufactured by INEOS Styrolution were used [41]. Table 2 provides its main physical properties, as given by the manufacturer, concerning injection molded parts.

\begin{tabular}{|c|c|}
\hline Properties & ABS \\
\hline Density $\left(\mathrm{g} / \mathrm{cm}^{3}\right)$ & 1.04 \\
\hline Tensile modulus $(\mathrm{GPa})$ & 2.3 \\
\hline Vicat Softening Temperature $\left({ }^{\circ} \mathrm{C}\right)$ & 95 \\
\hline Glass-transition temperature $\left({ }^{\circ} \mathrm{C}\right)$ & $105-115$ \\
\hline Melting-point temperature (injection) $\left({ }^{\circ} \mathrm{C}\right)$ & $110-125[42]$ \\
\hline
\end{tabular}

Table 2: Mechanical and physical properties of Terluran GP - 35 ABS as given in [41].

There is no standard specific test to determine the mechanical properties of PAM parts. In this study, the tensile properties have been characterized according to the NF EN ISO 527-2 standard. The dimensions of the specimens are shown in figure 2.

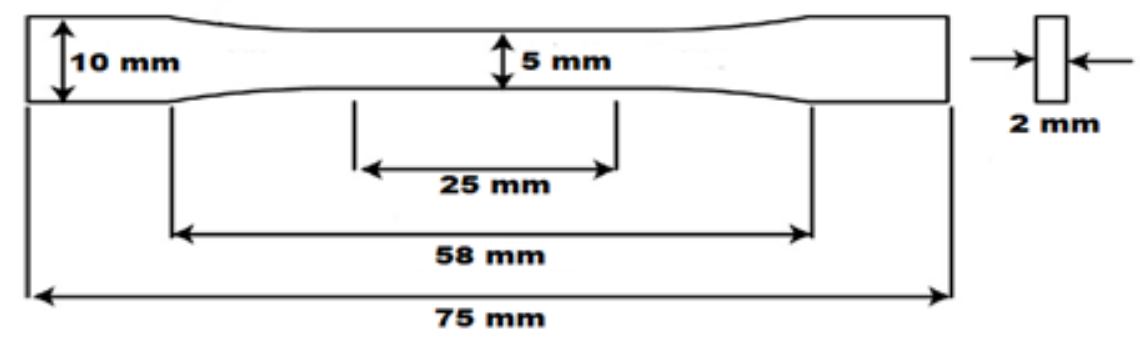

Figure 2: Geometry of the tensile specimens of this study, as specified by the ISO 527-2 standard.

The resulting stress-strain curves are presented in terms of the engineering strain $\varepsilon$ as provided by the extensometer and the engineering stress $\sigma=F / S$ where $F$ is the force exerted on the specimen and $\mathrm{S}$ is the initial gauge section.

\subsection{Printing parameters}


The specimen geometry was exported as an STL file and loaded into the Magics 3D printer slicing software package. The latter allows manufacturing parameters of the specimen to be modified. In particular, it allows parameters such as the printing orientation, the layer thickness, the properties of the deposited droplets (e.g. diameter, width/height ratio, etc.) and the infill degree of the part to be defined to a high degree of accuracy. It is important to pay great attention to this preparation step since possible errors in these parameters accumulate from layer to layer and may result in a defective part.

It should be noted that only the printing path was evaluated in this study. All ABS specimens were printed to a $100 \%$ infill degree. Doing this enables the comparison of the results obtained from the PAM process with those obtained by injection molding. Two types of printing sequences have been chosen for the tensile specimens: either 10 unidirectional layers or 10 layers alternating from one to the other by an angle of $90^{\circ}$ between two successive layers (crisscross printing). This has led to four different cases of printing orientation defined with respect to the axial loading direction of the specimens: $0^{\circ}, 90^{\circ}, 0^{\circ} / 90^{\circ}, 45^{\circ} / 45^{\circ}$. The axial specimen had 10 layers in the zero (loading) direction $\left[0^{\circ}\right]_{10}$, and the cross specimen were made from 5 repetitions of a $0^{\circ}$ layer (parallel to the tensile direction) and a $90^{\circ}$ layer (perpendicular to the tensile direction) $\left[0^{\circ} / 90^{\circ}\right]_{5}$. Default APF parts were made with a criss-cross layer in which the orientation of the beads alternates from $+45^{\circ}$ to $-45^{\circ}$ from layer to layer $\left[45^{\circ} /-45^{\circ}\right]_{5}$. Some transverse specimens $\left[90^{\circ}\right]_{10}$ were built and tested in addition to the main raster direction. They are illustrated in Figure 3 . The full set of printing parameters is summarized in Table 3.

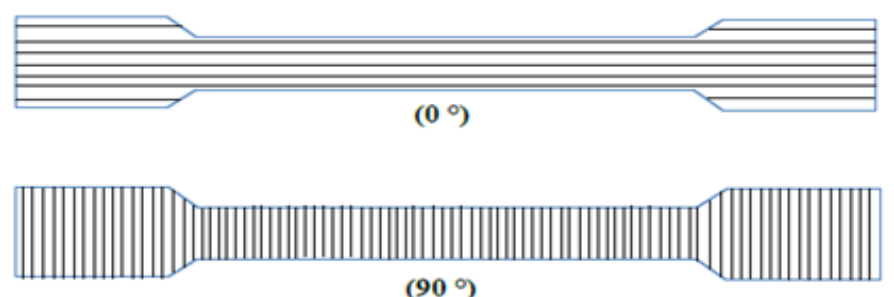

$\left(90^{\circ}\right)$

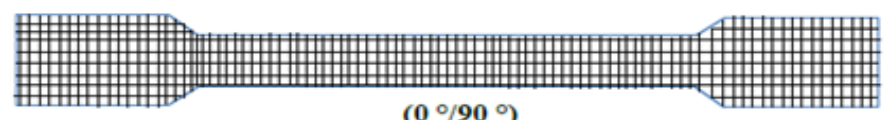

$\left(0^{\circ} / 90^{\circ}\right)$

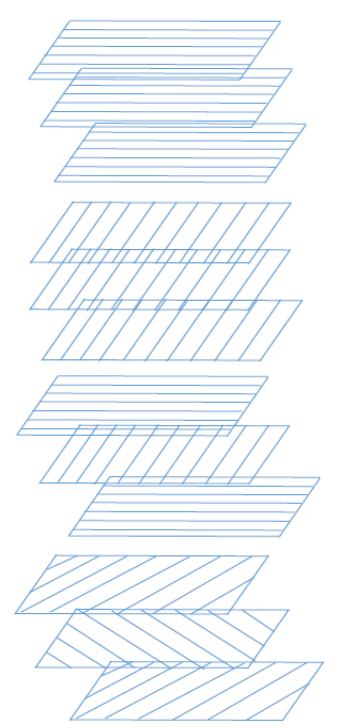

Figure 3: Illustration of the printing directions for the tensile test specimens manufactured via the APF process.

\begin{tabular}{|c|c|}
\hline Printing parameters & \\
\hline Path orientation $\left({ }^{\circ}\right)$ & $0,90,0 / 90,45 /-45$ \\
\hline Layer thickness $(\mathrm{mm})$ & 0.2 \\
\hline Infill degree $(\%)$ & 100 \\
\hline Number of layers & 10 \\
\hline Number of layers for the shell (contour) & 1 \\
\hline Nozzle temperature $\left({ }^{\circ} \mathrm{C}\right)$ & 230 \\
\hline Build chamber temperature $\left({ }^{\circ} \mathrm{C}\right)$ & 100 \\
\hline
\end{tabular}

Table 3: Printing parameters for the tested specimens. 


\subsection{Preparation protocol and tensile tests}

As shown e.g. in [38], moisture absorption adversely affects the mechanical performances of ABS printed components. In order to avoid any effect of moisture on the mechanical properties and, in the same time, to enable the relaxation of the microstructure of the material, the specimens had systematically been stored in a drying box at a constant temperature for one week just after their elaboration by APF or injection. The tensile tests were all been performed just after this storing period. It has been observed that without this preparation protocol a large dispersion on the tensile properties were obtained.

For each type of specimens (APF with different orientations, injection), five to seven replications were fabricated and tested. An MTS 810 electromechanical test machine with a 10 $\mathrm{kN}$ load cell was used for the tensile tests. The strain values of the test specimens were measured using a $25.4 \mathrm{~mm}$ gauge length extensometer. Specimens were loaded at a rate of $1 \mathrm{~mm} / \mathrm{min}$ and data from the load cell and extensometer were collected at a rate of $20 \mathrm{~Hz}$. Test were carried out at room temperature and $50 \%$ relative humidity $(\mathrm{RH})$ in conformity with ISO $527-2$.

\subsection{Microstructural observations}

The specimens were examined using scanning electron microscopy (Zeiss LEO 1530 XB Crossbeam SEM) with operating voltage of $10 \mathrm{kV}$ to gain insights into the internal structure of the consolidated specimens and to examine their failure mechanisms. ABS being an electrical insulator, each specimen was gold coated prior to SEM observation. Additionally, in order to better understand the effects of the printing path on the specimen failure modes, optical microscopic inspection was performed using a Keyence VHX-600 DIGITAL 3D optical microscope. Furthermore, the microstructure of printed specimens were characterized by means of X-ray microtomography. The image acquisition was achieved using a SkyScan Xray micro-CT system. The measurements were performed with a $160 \mathrm{kV} X$-ray source with an acceleration voltage of $60 \mathrm{kV}$ and a beam current of $167 \mu \mathrm{A}$. The selected regions of interest (ROI) had volumes of approximately $5 \times 5 \times 3 \mathrm{~mm}^{3} .1095$ radiographic images were taken and their respective image resolutions were $2000 \times 1200$ pixels. The Ct-analyser software CTAn was used to derive quantitative parameters and to construct $3 \mathrm{D}$ visual models from the $2 \mathrm{D}$ scans. The image acquisition and image processing was conducted in the laboratory "Analyses and Surfaces" (Centre de Ressources Technologiques, Val de Reuil, France).

\section{Results and discussion}

For the specimens elaborated by APF, the layers were overlaid by selecting a certain raster angle. It can be assumed that in view of this particular arrangement of the layers relative to each other, the mechanical properties of the resulting material might depend on the chosen orientation. An analogy has been proposed by Carneiro et al. [32] between the tensile behavior of laminated composites specimens and those obtained by the FDM technique. Indeed, as for a laminate where the orthotropic elastic behavior is directly related to the arrangement of fibers, 
the elastic behavior of a volume element produced by FDM can be thought to be related with the direction of deposition. This analogy should however be interpreted with caution: although there are common points between laminated composites and layer-by-layer deposition, the differences are significant. Contrary to composites, a single material is used for the specimens in this study. Therefore, there is no heterogeneity in the composition of the specimen and there is no sense in considering fiber-matrix decohesion or delamination mechanisms.

\subsection{Influence of deposition path on the tensile properties}

The resulting stress-strain diagrams for the six injection molded specimens are shown in Figure 4. We can note that these curves present a quasi-linear elastic portion up to $2 \%$ strain followed by yielding deformation until specimen failure. It can be seen that, after the stress had reached its peak, the resisting stress was nearly constant with the increase in deformation. These results are in agreement with those cited in the literature [43] for the ABS part manufactured via the FDM process. The tested specimens exhibited a very high repeatability in their respective ultimate tensile stress and elastic modulus values. On the contrary the strain until failure of these samples varies considerably.

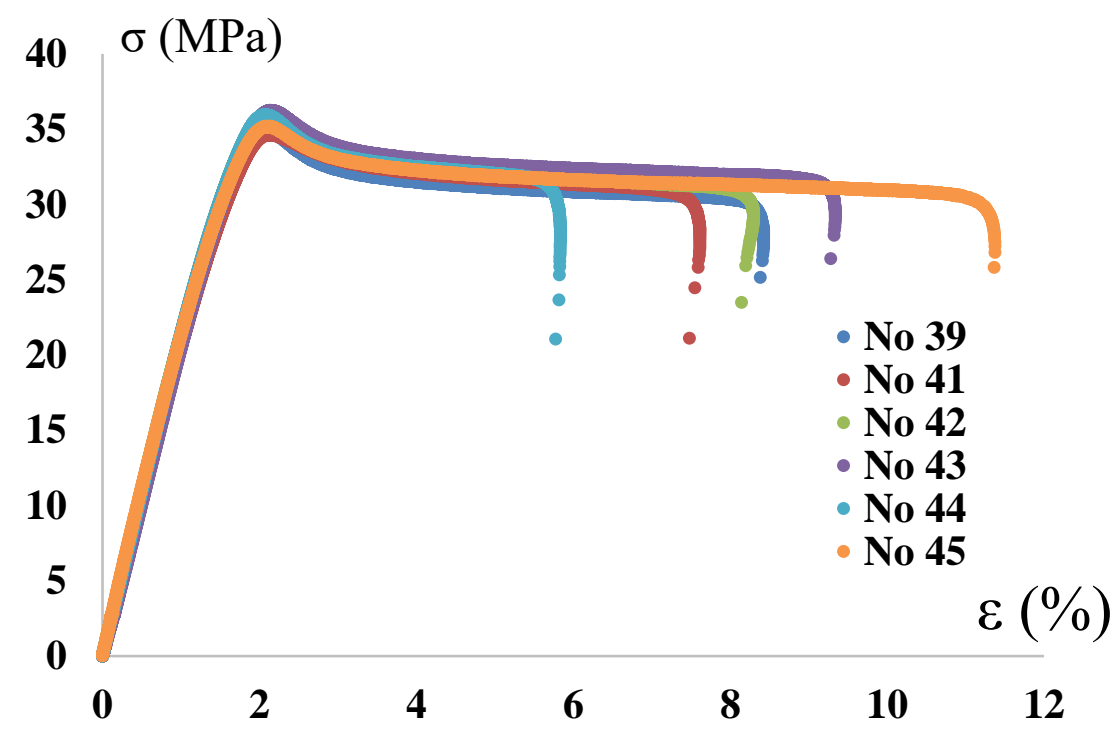

Figure 4: Tensile stress-strain curves of the specimens elaborated by injection molding.

Figure 5 shows the resulting stress-strain curves of the specimens elaborated by APF. A similar response can be observed for all the tested specimens: a linear elastic behavior stage from 0 to $2 \%$ of strain, up to the ultimate tensile stress (UTS), then a small stress drop followed by an increase of the deformation at a constant stress, and then yielding, characterized by the strain to failure. As a first observation, it is noted that the deposition orientation significantly affects the dispersion of the yield deformation: it is much larger for specimens of the class $\left[90^{\circ}\right]$ or $\left[0^{\circ} / 90^{\circ}\right]$ than for the others. The $\left[0^{\circ} / 90^{\circ}\right]$ case is also the one which displays the largest dispersion in UTS. Amongst all, the $\left[-45^{\circ} / 45^{\circ}\right]$ case is the one which presents the smallest dispersion in both strain to failure and UTS, and these dispersions are of the same order than those of the injection molded specimens. 

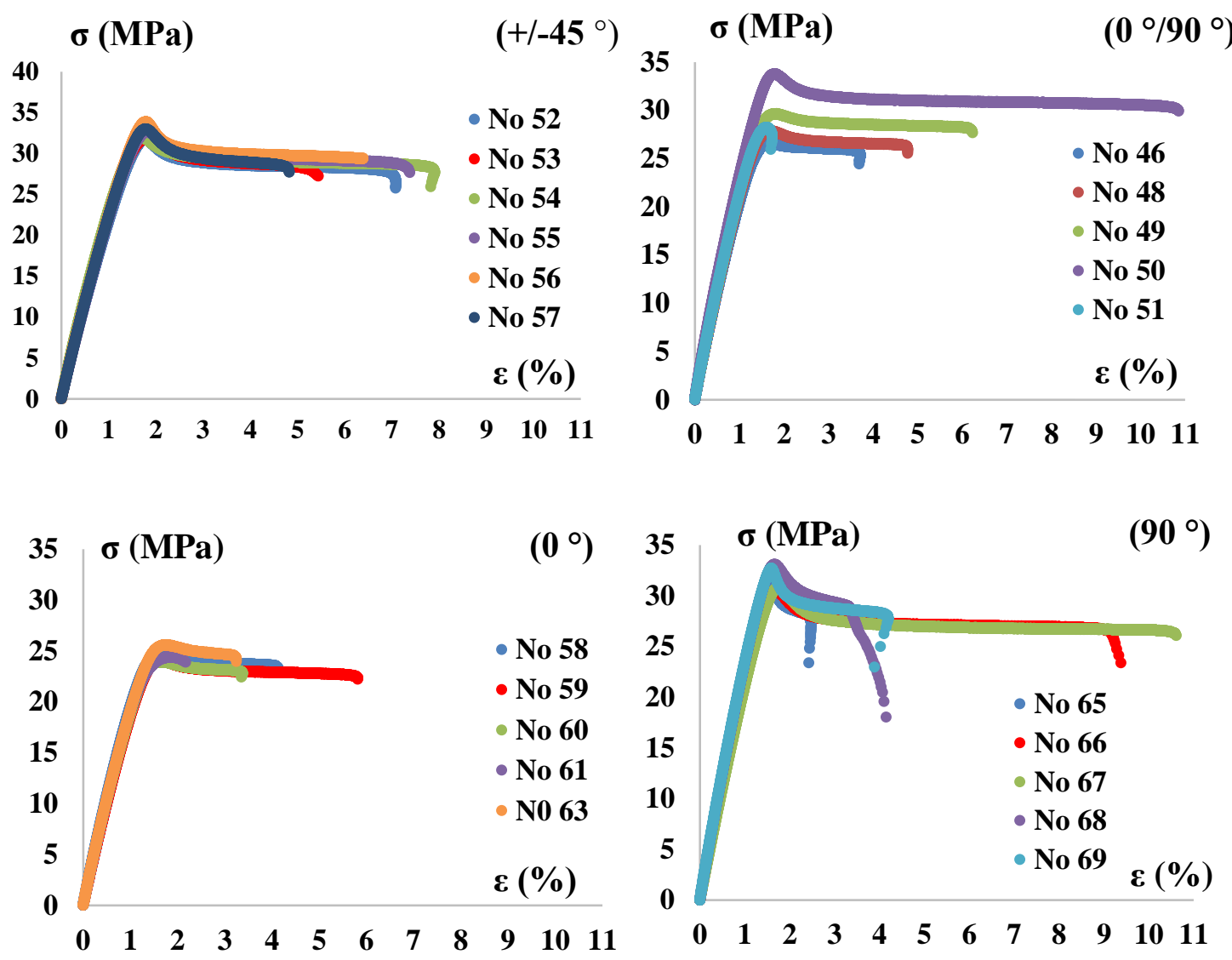

Figure 5: Tensile stress-strain curves of the specimens elaborated by APF.

In Figure 6, the UTS $\left(\boldsymbol{\sigma}_{\mathbf{m}}\right)$, the strains to failure $\left(\boldsymbol{\varepsilon}_{\mathbf{m}}\right)$ and the tensile elastic moduli $(\mathbf{E})$ of the specimens elaborated by APF and by injection molding are compared in order to evaluate the influence of the processing method on the resulting tensile properties. The obtained results can also be compared to the reference values provided by the ABS supplier. These values, referred to as "datasheet" in figure 6, have been measured from injection molded specimens. As a first observation it is noticed that whatever the considered property the obtained value is always smaller than in the reference datasheet, even for injection molded specimens. This could be due to differences in the elaboration setup and parameters between the present study and that performed by the ABS supplier.

Focusing then on the results of the present study, it is seen that the printing orientation significantly affects the strain to failure, whatever the printing direction. Concerning UTS and stiffness, this effect is smaller. The injection molded ABS tested in this study exhibits a UTS of $35.4 \mathrm{MPa}$, whereas for APF specimen it varies between $69 \%(24.4 \mathrm{MPa})$ and $92 \%(32.4$ $\mathrm{MPa})$ of this value, depending on the orientation of the raster. These results were in line with those reported in the literature for the ABS material manufactured with FDM under different printing conditions [31], [38]. Knowing that all the APF specimens were printed with a $100 \%$ infill degree, this difference could be due to the different manufacturing routes. Tiny thermoplastic droplets were deposited in the APF process whereas in injection molding the liquefied thermoplastic was introduced into the mold cavity without strong temperatures gradients. As a consequence of this, the microstructure of the test specimens obtained via the two methods cannot be the same; injection molding produces far more isotropic specimens than the additive manufacturing process. 
Focusing now on the differences between the different APF classes, the $\left[0^{\circ}\right]$ class appears to have overall degraded properties (viz. lowest ductility, stiffness and strength). Although the only difference with the $\left[90^{\circ}\right]$ class is the direction of loading with respect to the printing direction, a significant decrease in UTS and stiffness is observed. This highlights an anisotropy in the behavior which is related to the formation of bonds between droplets and beads during the APF process: the interfacial bonding between two adjacent beads is stiffer than the interfacial bonding between two consecutive droplets of a same bead. Bellehumeur et al. [44] have described the formation of bonds between polymer filaments in the FDM process. They explained that the first step of bond formation is the establishment of interfacial molecular contact by wetting. The molecules then undergo motions towards preferred configurations to achieve an adsorptive equilibrium. Molecules diffuse across the interface, forming an interfacial zone, and/or react to form primary chemical bonds across the interface. The randomization can be reached only after extensive inter-diffusion of chain segments under critical conditions. In another study, Sood et al. [45] have clarified that a small air gap helps to create a strong bond between the two rasters and thus improves the strength of the component. But a small air gap restricts heat dissipation; thus increasing the chance of stress accumulation.
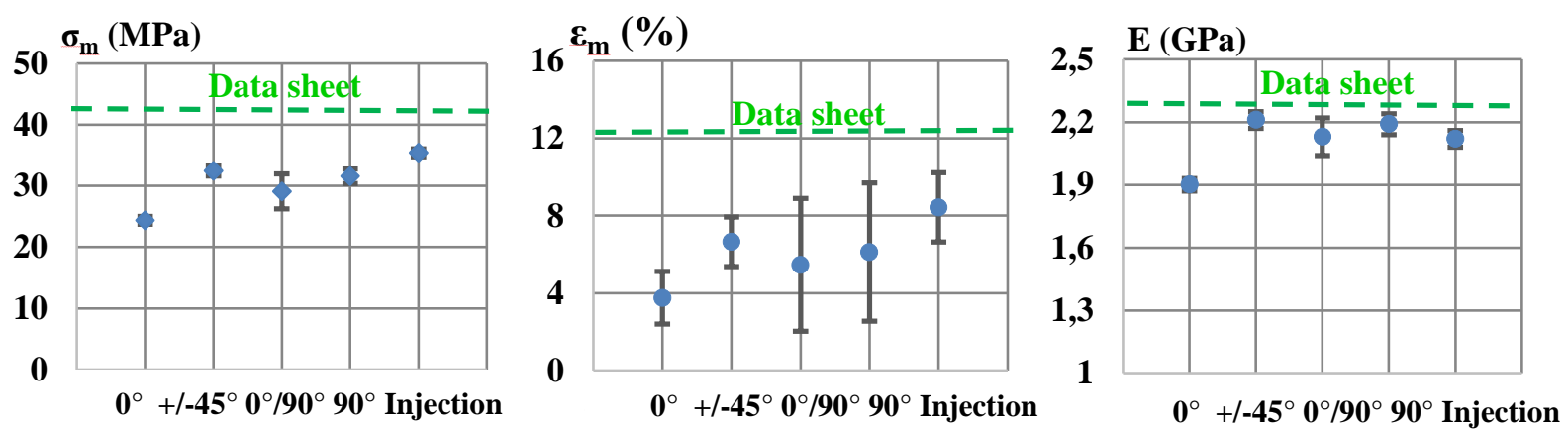

Figure 6: Comparison of the tensile properties obtained according to the different processing techniques: from left to right, ultimate tensile stress, strain to failure and Young's modulus.

\subsection{Fractographic analysis}

To better understand the influence of process parameters on the failure modes of the specimens, microscopic images of the specimens fracture surfaces were evaluated. SEM images of an APF $0^{\circ}$ specimen are shown in Figure 7 . Three zones can be defined across the cross-section.

In zone A (Figure 7a), macro and micro voids can be found. These characterize the cavities between the layers and the porosities within the droplets respectively. The presence of porosities in zone B, which is located in the middle of specimen (Figure 7b), decreases significantly. In zone C (Figure 7c), the presence of cavities or interlayer spacing is more noticeable. In contrast, the porosities are not present within the droplets in this zone. The deposited beads consist of a succession of drops (here in the slice) and cannot be assimilated to the fibers in a laminate or to a filament in a FDM specimen. Figure 7c shows a drop diameter problem: some drops have a smaller diameter than the set point, creating additional voids. This latter problem can be suspected to occur due to machine instability. 


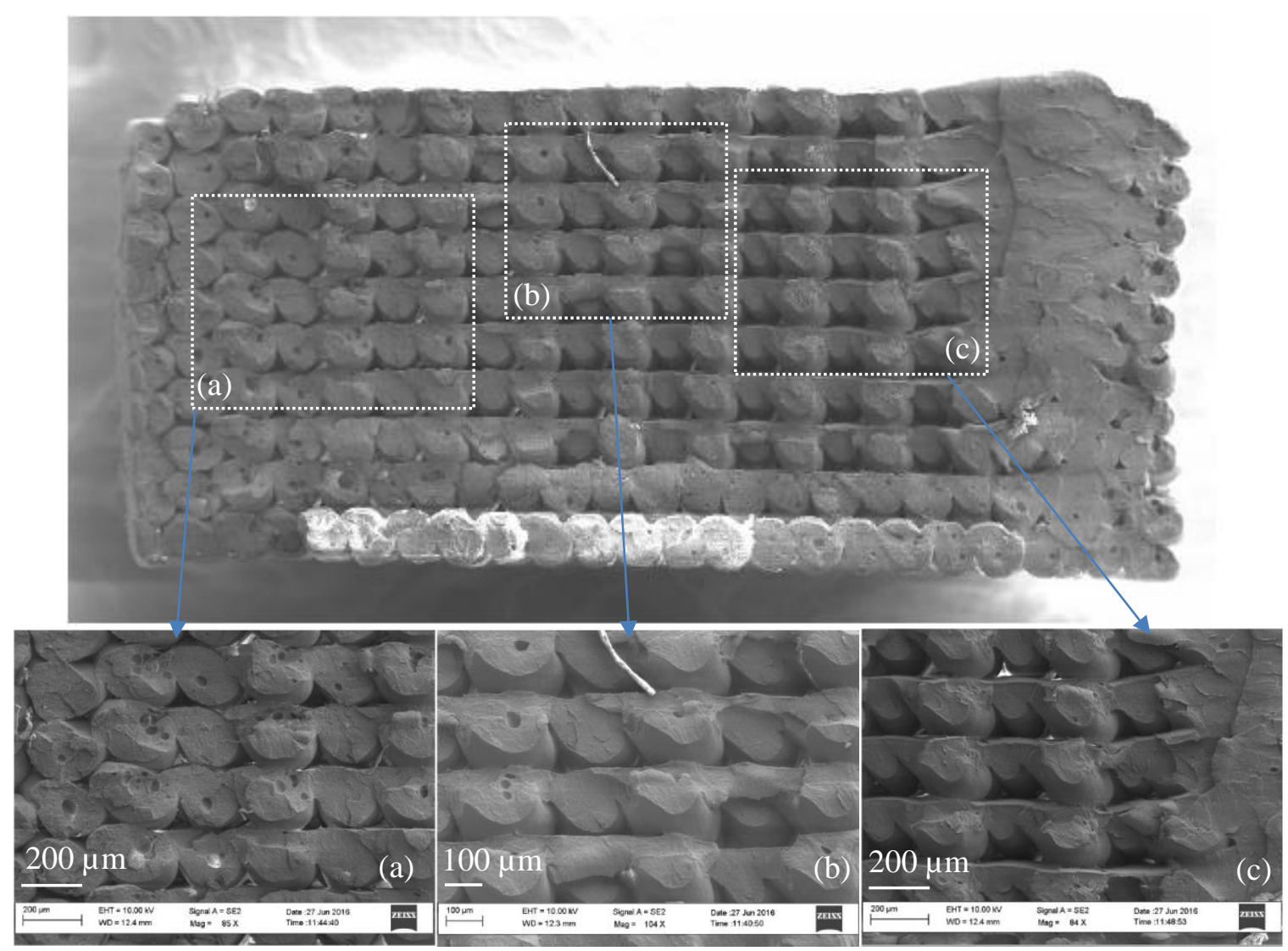

Figure 7: SEM scans of the fractured surfaces of a $0^{\circ}$ APF specimen.

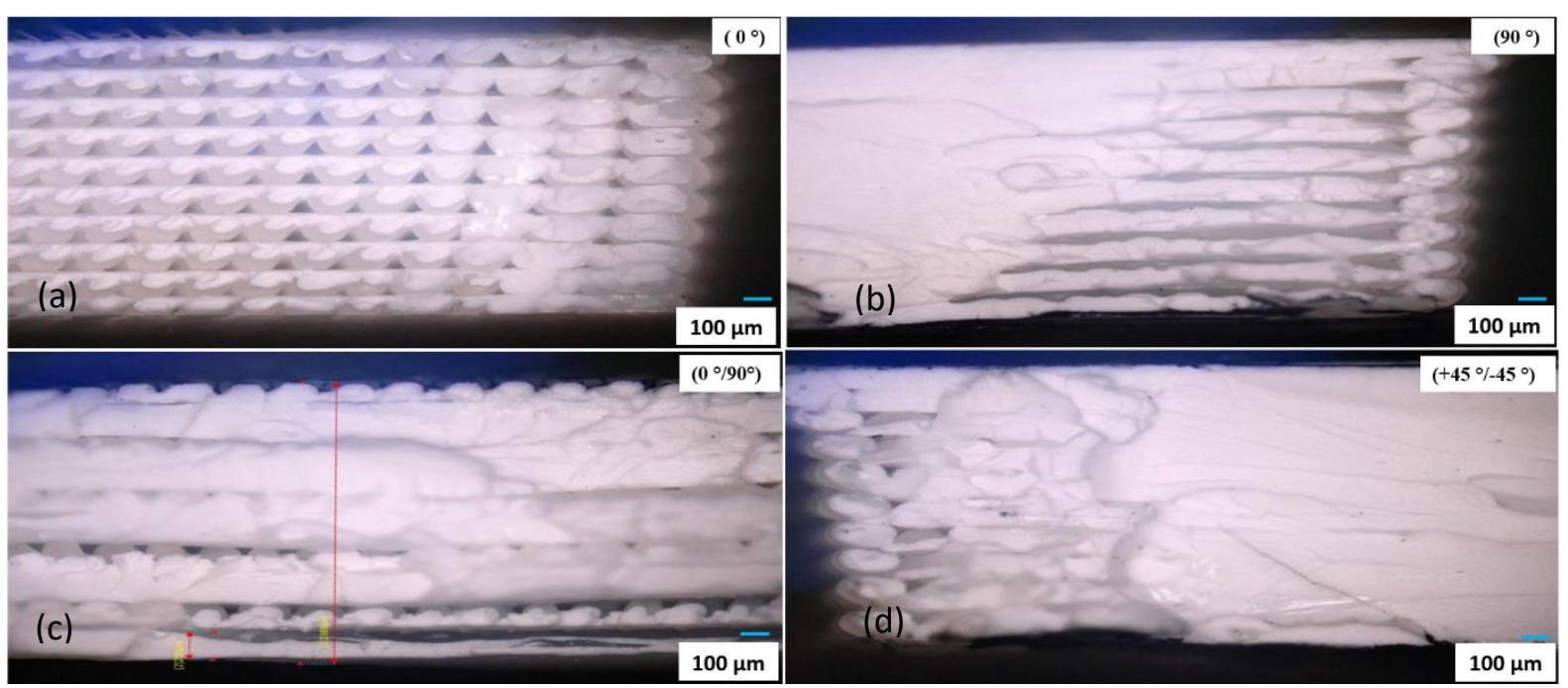

Figure 8: Optical microscopy scans of the fractured surfaces of specimens elaborated by APF with the different printing directions.

Optical microscope inspection of the fracture surfaces of specimens printed with different orientations are shown in figure 8. They show that failure has different origins. Although individual ABS layers have melted together, every layer can still be distinguished in these images, and the fracture was mainly caused by pulling and rupturing damage to the layers. Generally, the fracture of the additive manufactured specimens began in close proximity to the weakest layers, and the cracks propagated up to complete specimens failure. Comparison of fracture surfaces shows that the failure modes have changed according to the layer orientation. In particular, the $0^{\circ}$ specimen gave rise to a more discontinuous surface area, resulting in 
reduced elongation to fracture, and it seems to be related to a higher observable amount of porosities on the fracture surface.

Figure 9 shows a magnified view of the fracture surface of an injection molded ABS specimen. In most cases, the fracture of this thermoplastic component is ductile due to the reorientation and stretching of the thread-like macromolecules that allow for high levels of material deformation. In this case thermoplastics are being investigated, and so one would expect to see typical ductile fracture characteristics in these specimens. Multiple craters and voids can be observed on the fracture surface. The fracture surface is nearly flat and without necking. Compared to the printed specimens, a significant difference in the size of porosities can be observed: circular cavities with diameters lower than $1 \mu \mathrm{m}$ are found in the molded specimen. Furthermore, the fracture surface of the molded specimen exhibits a number of cavities with a more uniform diameter distribution along the surface.

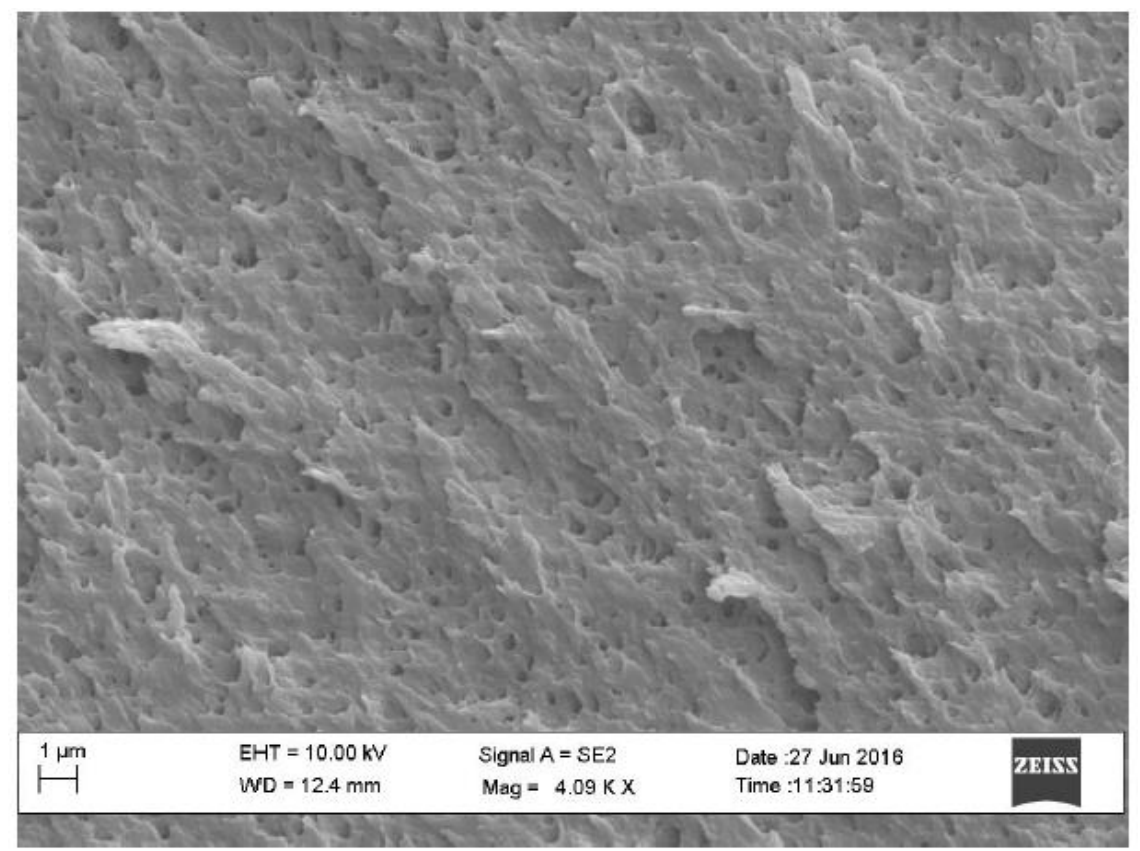

Figure 9: SEM scan of the specimen elaborated by injection molding.

\subsection{X-ray microtomography analyses}

Structural defects in the printed specimens were analysed by means of X-ray microtomography. This 3D analysis tool allows to study the correlations between the APF processing parameters and the 3D microstructural features and afterwards the mechanical properties of the specimens. To this purpose, image analysis was applied to the 3D printed slabs in order to measure both the structural attributes - such as porosity volume fraction- and to identify defects in a three-dimensional space. Some other microstructural features, such as porosity size, form, length and orientation, were obtained from 2D analyses. Two printing procedures have been investigated: a unidirectional one (which is representative of $\left[0^{\circ}\right]$ and $\left[90^{\circ}\right]$ specimens) and criss-cross printing with $90^{\circ}$ rotation from layer to layer (which is representative of $\left[0^{\circ} / 90^{\circ}\right]$ and $\left[45^{\circ} / 45^{\circ}\right]$ specimens).

The analysed tomography specimens have the shape of parallelepipedic bricks. In all the following figures, they are placed within the $(\mathrm{X}, \mathrm{Y}, \mathrm{Z})$ framework where $\mathrm{Z}$ is the building direction (a deposition layer is thus contained within the $(\mathrm{X}, \mathrm{Y})$ plane) and $\mathrm{X}$ is the printing 
direction for the unidirectional printing; the criss-cross printing corresponds to printing directions at $-45^{\circ}$ and $45^{\circ}$ from the $\mathrm{X}$ axis.

As seen on Figure 10a, the porosity surface fraction on the outer YZ face is higher in the upper half of the $\left[0^{\circ}\right]$ specimen, furthermore the pore size is not uniform. The degraded mechanical properties of the $\left[0^{\circ}\right]$ tensile specimens could be related to this heterogeneity: pore coalescence could accelerate crack formation and initiate the damage process. Figure 10b displays another view in the $\mathrm{XZ}$ outer faces of the specimens. It confirms the greater porosity content for the axial $\left[0^{\circ}\right]$ specimens. Besides, this $\mathrm{XZ}$ view highlights a quasi uniform distribution of pores in the $\left[0^{\circ}\right]$ specimen, in the form of a square array directly related to the deposition process, whereas a non-uniform distribution is observed for the $\left[-45^{\circ}, 45^{\circ}\right]$ printing. In the XY views of the specimens (upper faces, on Figure 10c) the pore surface fraction is greater in the middle of the $\left[-45^{\circ} / 45^{\circ}\right]$ specimen whereas concerning the $\left[0^{\circ}\right]$ specimen, most of the pores are observed along the edges.
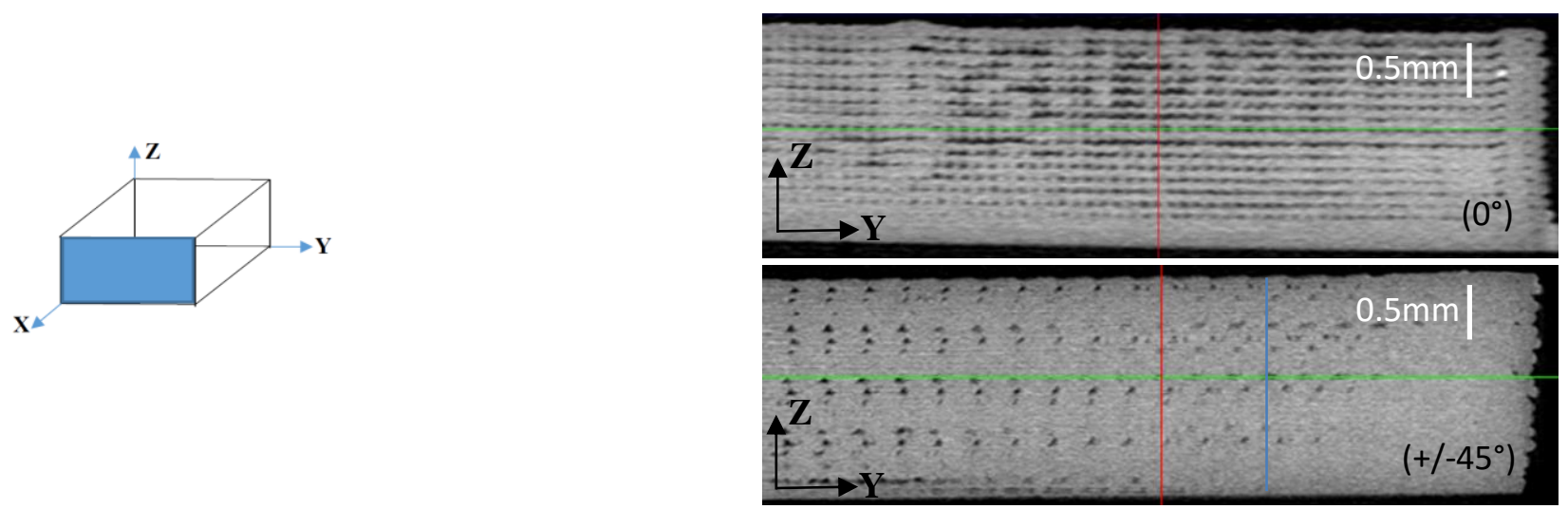

(a)
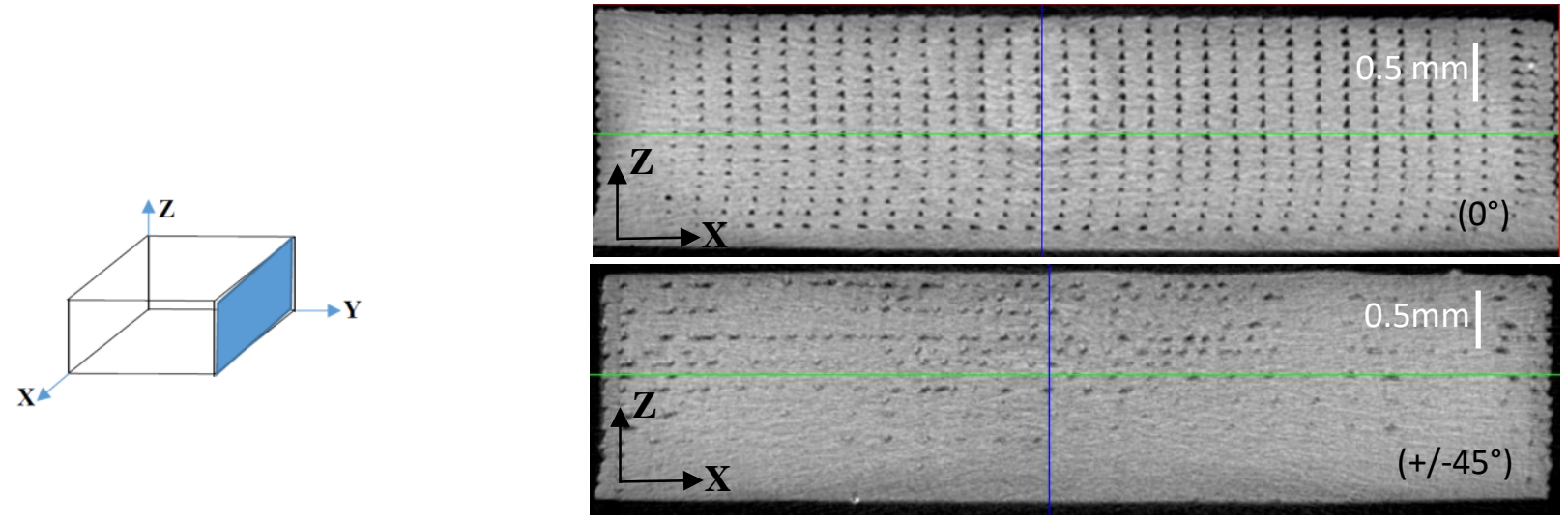

(b) 

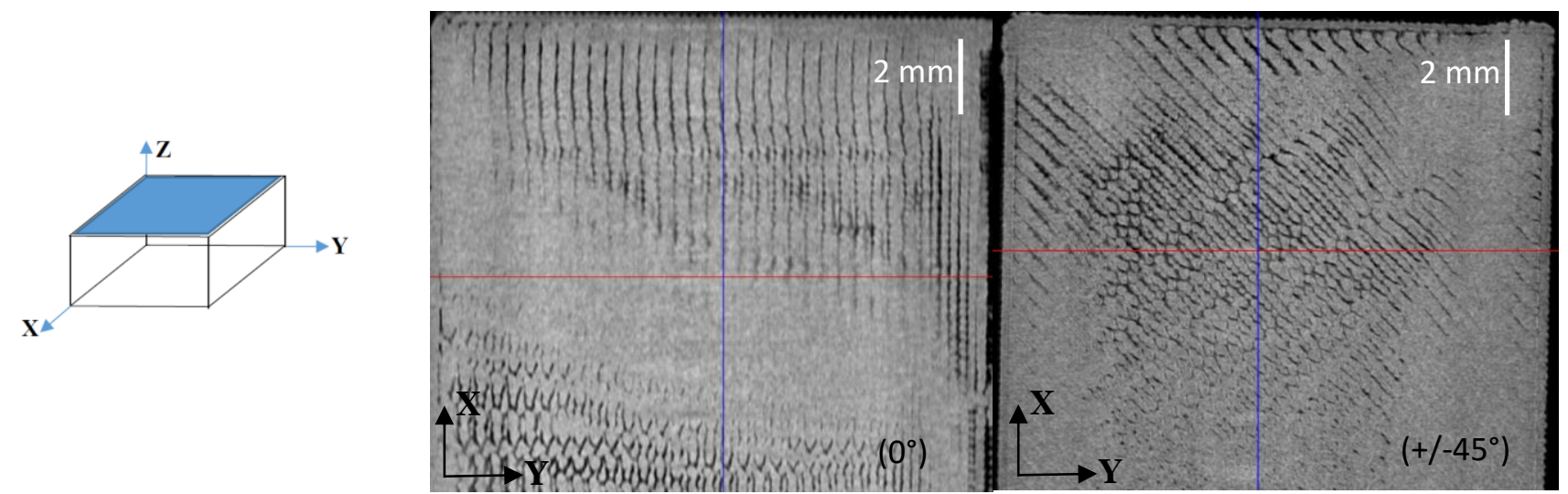

(c)

Figure 10: Tomography scans of the external faces of the samples printed at $0^{\circ}$ and $-45^{\circ} / 45^{\circ}$ from the $\mathrm{X}$ axis. $\mathrm{Z}$ is the building direction. The left column describes the orientation of the analysed face.

Considering now the outer surfaces of the tomography specimens as reconstructed in $3 \mathrm{D}$, on Figure 11, it is noted that the maximum pore size is considerably smaller for the unidirectional $\left[0^{\circ}\right]$ specimen than for the criss-cross specimen: the phenomenon of pore coalescence is more significant in the criss-cross specimens, which could be caused by the toolpath crossing in a $+/-45^{\circ}$ deposition sequence. This observation is in line with the observation of a quite accurate periodic repetition of pores in the unidirectional printing. It is further remarked that at this stage of the tomography analysis, considering either $2 \mathrm{D}$ scans or a 3D reconstruction of the outer contours may not lead to the same conclusion regarding which of the specimens displays the largest proportion of pores. It is however confirmed that the pores are more dispersed with the criss-cross printing, concerning both their spatial distribution and their sizes.

De facto, this 3D reconstruction enables to measure the total volume fraction of pores in each printing case: $8.2 \%$ for the unidirectional printing path and $3.1 \%$ for the criss-cross one. These pore volume fractions explain partially the differences in Young moduli which have been measured in tension. At least qualitatively: as classically assumed in elastic damage theory, the effective Young modulus of a damaged material $\mathrm{E}_{\text {eff }}$ is proportional to the volume fraction of pores $p$ : $E_{\text {eff }}=(1-p) * E_{\text {ini }}$ where $E_{\text {ini }}$ is the Young's modulus of the undamaged material. So the

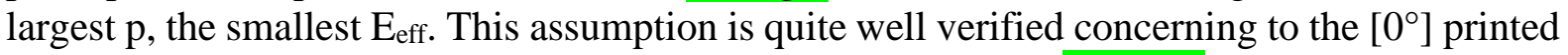
tensile specimens since a decrease of approximately $8 \%$ in the Young's modulus is observed between injection molded specimens and $\left[0^{\circ}\right]$ specimens. But it does not stand for the other printing orientations; the inverse effect is even found since, despite the presence of a larger amount of pores, these other printing cases feature larger stiffnesses than the injection molded specimens. Furthermore the $\left[0^{\circ} / 90^{\circ}\right]$ specimens, although significantly more dense, happen to be smoother than the $\left[90^{\circ}\right]$ ones. 

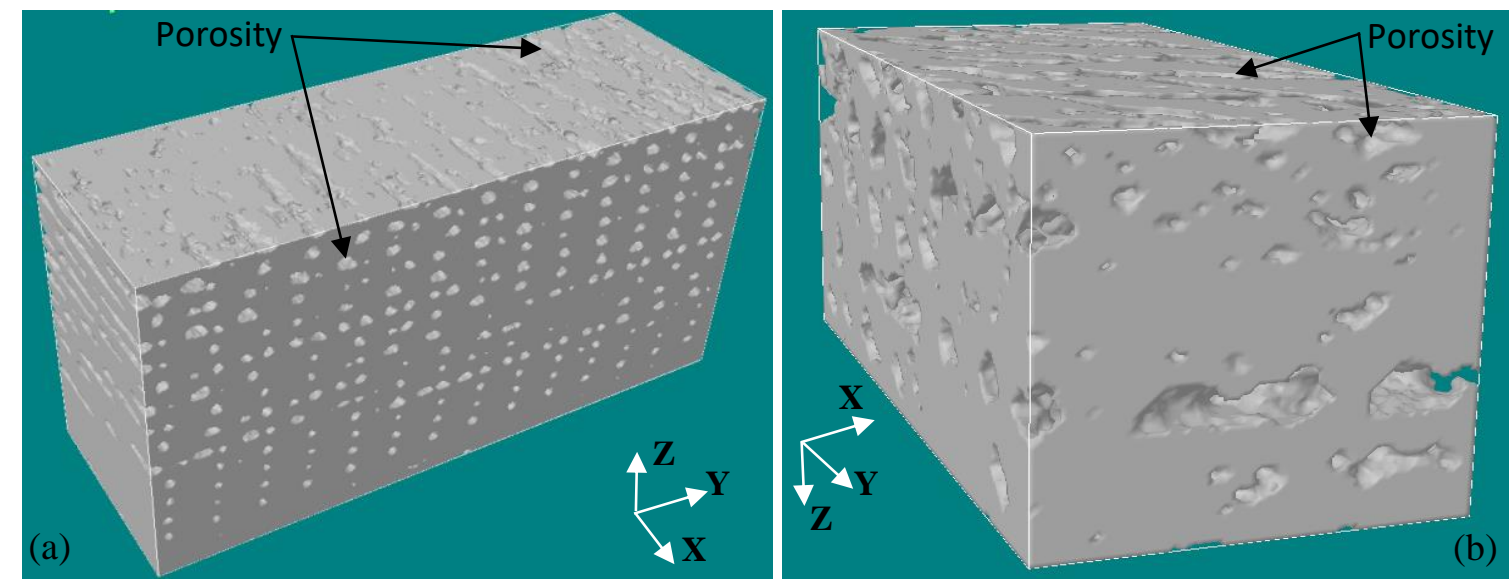

Figure 11: View on the external surfaces of the 3D reconstructed tomography specimens. (a)

Unidirectional $\left[0^{\circ}\right]$ printing. (b) Criss-cross $\left[-45^{\circ} / 45^{\circ}\right]$ printing.

These results show that it is not sufficient to consider the porosity volume fraction to extrapolate the stiffness of a printed specimen from the stiffness of an injection molded material and from the volume fraction of pores.

As previously remarked, the anisotropy in the cohesion forces (larger between two adjacent deposition beads than between two consecutive droplets of a same bead), which is intrinsic to the whole printing process (from the granulates extrusion to the deposition and cooling on the build part) may play an important role in the stiffness of the material. But the three-dimensional network of pores may also play a role, and not only on the stiffness. To analyse this role, Figure 12 provides different views on the 3D porosity networks inside the specimens, with increasing details from top to bottom. One may recognize the direct relation between the printing direction and the porosity network: the overall views in Figure 12a,b features networks which seem to be periodically distributed in the specimens and oriented according to the printing path. This is confirmed by displaying the porosity network at varying height of the specimens: the $3 \mathrm{D}$ network is structured in $2 \mathrm{D}$ quasi planar layers of pores which are superimposed along the $\mathrm{Z}$ direction. Figure 12c,d provides scans of a typical 2D layer in each printing case. Once again a structuration of the porosity layer is observed, strongly related to the printing path: it corresponds to more or less continuous channels along the direction of printing. In the $\left[0^{\circ}\right]$ case, the continuity (or connectivity) can even be observed from side to side of the specimen along the printing direction; in the $\left[-45^{\circ} / 45^{\circ}\right]$ case the porosity channels are significantly shorter. It is further noticed in this latter case that there is no connectivity of the channels from side to side of the specimen, neither along the printing direction $\left(45^{\circ}\right.$ wrt $\left.\mathrm{X}\right)$ nor along the $\mathrm{X}$ direction (which corresponds to the loading direction in the tensile tests). This relation between the printing direction and the porosity connectivity along the $\mathrm{X}$ direction provides a first explanation on the degraded tensile properties of the $\left[0^{\circ}\right]$ tensile specimens as compared to the $\left[-45^{\circ} / 45^{\circ}\right]$ specimens.

Considering now the in-plane connectivity along the direction at the perpendicular to the printing direction (Figure 12c,d), a few bridges can be found between two channels in the $\left[-45^{\circ} / 45^{\circ}\right]$ case and much more are found in the $\left[0^{\circ}\right]$ case. This indicates that alternating the 
printing of a layer with another one at $\left[90^{\circ}\right]$ does not only enable to reduce the mean volume fraction of pores but also considerably reduces the connectivity of pores in the direction perpendicular to the printing. Figure $12 \mathrm{e}, \mathrm{f}$ enables to confirm the propensity of criss-cross printing to reduce pores network connectivity: they show that out-of-plane bridges exist between two in-plane porosity layers in the unidirectional printing case but none can be seen in the criss-cross printing case.
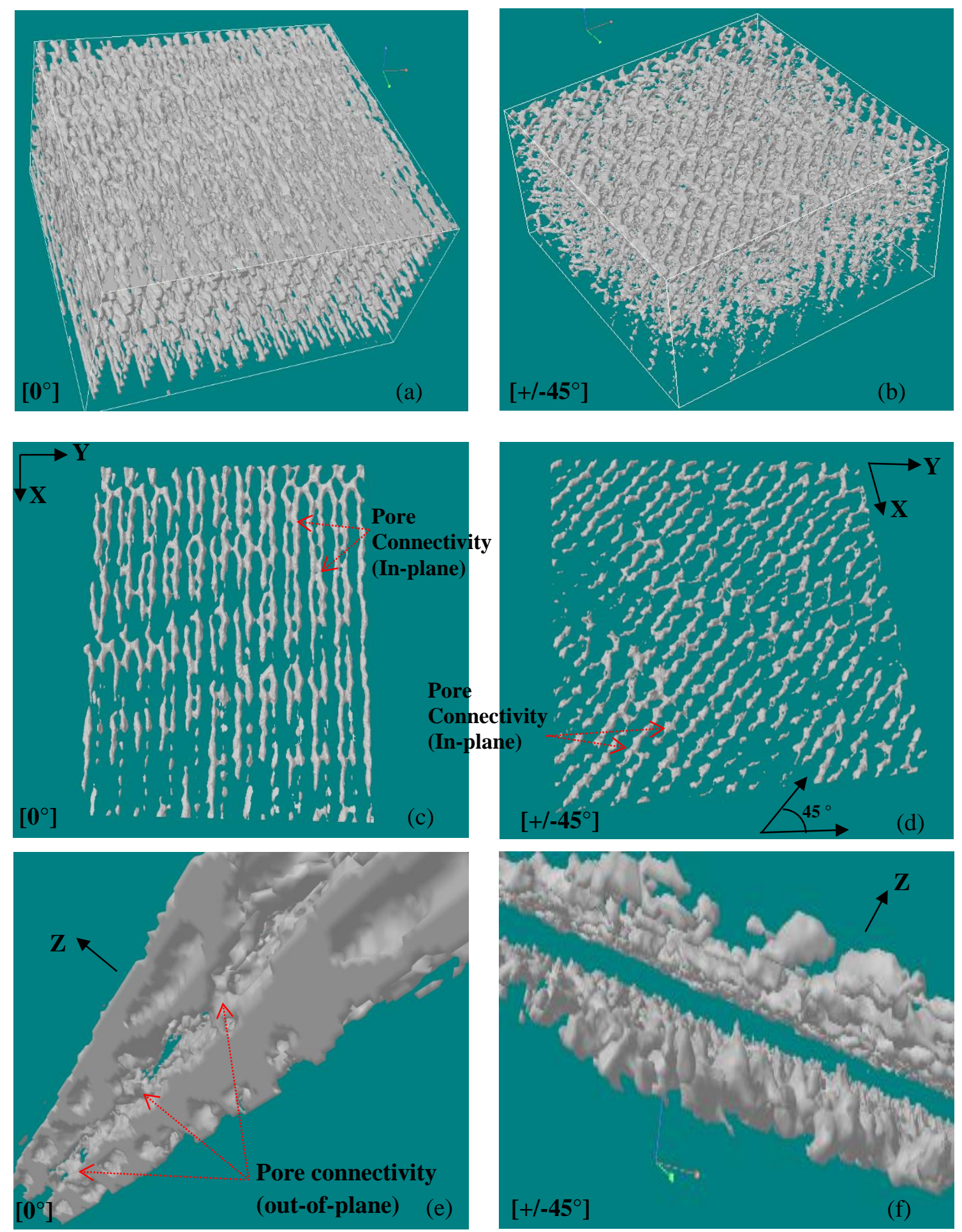
Figure $12: 3 \mathrm{D}$ reconstruction of the porosity network. (Left) unidirectional $\left[0^{\circ}\right]$ printing, (Right) crisscross $\left[-45^{\circ} / 45^{\circ}\right]$ printing. Views on the overall specimens (top), on single porosity layers (middle) and, zoomed, on the out-of-plane porosity connectivity between two successive deposition layers (bottom).

Focusing on the unidirectional case, the strong anisotropy of the porosity network can be thought to be responsible for the strong differences in the tensile behavior of the $\left[0^{\circ}\right]$ tensile specimens and the $\left[90^{\circ}\right]$ ones. But it cannot be the only source of differences: although $\left[90^{\circ}\right]$ tensile specimens figure out a higher volume fraction of pores and higher pore connectivity distances (in the three principal directions of the specimen) than criss-cross specimens, they display tensile properties which are close to those of the criss-cross specimens.

\section{Conclusions}

The analysis performed in this study is meant at characterizing the effect of printing direction on the tensile properties of an ABS printed with the Arburg-Plastic-Freeforming technology. To this end four cases of printing have been considered, which are defined by the angle between the printing direction in a layer and the direction of tension: (i) $0^{\circ}$ or (ii) $90^{\circ}$ for all the layers, (iii) layers at $0^{\circ}$ and $90^{\circ}$ alternating from a layer to its upper one and (iv) layers at $-45^{\circ}$ and $45^{\circ}$ from a layer to its upper one. An experimental analysis protocol have been defined, including the preparation, the storage, and the comparison of properties to injection molded specimens of the same ABS. Tensile tests have been performed on sets of at least 5 specimens for each considered elaboration case and their results have been compared in terms of stiffness (Young's modulus), ultimate tensile stress (UTS) and elongation to fracture. The analyses have been pursued on the fracture surfaces of the specimens to characterize the modes of fracture and tomography $3 \mathrm{D}$ analyses have been performed to determine whether a relation could exist between the printing direction, the porosity network and the tensile properties.

The fracture surfaces analyses have highlighted the microstructuration of the material into layers, beads and droplets and the probable relation between microstructure defaults and fracture process. They have revealed the presence of macro-voids between the printed layers and micro-voids within the droplets. X-ray tomography analyses have confirmed the presence of a porosity network which is structured according to the printing path and whose connectivity distances are strongly dependent on the angle between two successive layers: alternating the printing direction by an angle of $90^{\circ}$ from a layer to its upper one considerably reduces both the total volume fraction of pores and the connectivity distances, especially along the building direction.

However the porosity network and its structuration according to the printing-direction cannot explain in itself the effect of the printing trajectory on the tensile properties. The mean properties of the $\left[90^{\circ}\right]$ specimens indeed appeared to be quite similar to those of the $\left[0^{\circ} /-90^{\circ}\right]$ and $\left[45^{\circ} / 45^{\circ}\right]$ ones, despite the higher porosity volume fraction and the largest porosity connectivity distances. The difference in the cohesion forces between two successive droplets of a same bead or between two adjacent beads of a same layer can also be an important factor to explain the strong anisotropy of the tensile properties in the case of the unidirectional printing $\left(0^{\circ}\right.$ and $\left.90^{\circ}\right)$.

Finally, whereas the $\left[0^{\circ}\right]$ printing case appeared to provide the weakest tensile properties in terms of mean stiffness, elongation to fracture and UTS, any case where a printing at $90^{\circ}$ was made $\left(\left[90^{\circ}\right]\right.$ and $\left.\left[0^{\circ} / 90^{\circ}\right]\right)$ has led to a large dispersion in the measured properties and only the 
case $\left[-45^{\circ} / 45^{\circ}\right]$ provides tensile properties which are comparable to those of the injection molded specimens, both concerning the mean measures and the dispersion of measures. As observed with FDM, the elongation to fracture is reduced but by less than $20 \%$.

\section{Acknowledgements}

This research study is a part of the SCAMPI project which is co-financed by the Normandy Region and the European Regional Development Fund. We are grateful to L. Chevalier and C. Keller for their assistance in taking SEM images. The X-ray microtomography analyses were performed at the laboratory "Analyses \& Surface". M. Boulay is thanked for her assistance in these treatments. We thank E. Baustert (VOLUM-e) for his suggestion and the exchange of ideas on the general subject of additive manufacturing.

\section{References}

[1] Espalin D, Muse DW, MacDonald E, Wicker RB. 3D Printing multifunctionality: structures with electronics. Int J Adv Manuf Technol 2014;72:963-8. doi:10.1007/s00170-0145717-7.

[2] Yang Y, Chen Y, Wei Y, Li Y. 3D printing of shape memory polymer for functional part fabrication. Int J Adv Manuf Technol 2016;84:2079-95. doi:10.1007/s00170-015-7843-2.

[3] Melenka GW, Schofield JS, Dawson MR, Carey JP. Evaluation of dimensional accuracy and material properties of the MakerBot 3D desktop printer. Rapid Prototyp $\mathrm{J}$ 2015;21:618-27. doi:10.1108/RPJ-09-2013-0093.

[4] Singh M, Haverinen HM, Dhagat P, Jabbour GE. Inkjet Printing-Process and Its Applications, Adv Mater 2010;22:673-85. doi:10.1002/adma.200901141.

[5] Blanco D, Fernandez P, Noriega A. Nonisotropic experimental characterization of the relaxation modulus for PolyJet manufactured parts. J Mater Res 2014;29:1876-82. doi:10.1557/jmr.2014.200.

[6] Gay P, Blanco D, Pelayo F, Noriega A, Fernández P. Analysis of Factors Influencing the Mechanical Properties of Flat PolyJet Manufactured Parts. Procedia Eng 2015;132:70-7. doi:10.1016/j.proeng.2015.12.481.

[7] Cazón A, Morer P, Matey L. PolyJet technology for product prototyping: Tensile strength and surface roughness properties, Proc Inst Mech Eng Part B J Eng Manuf 2014;228:1664-75. doi:10.1177/0954405413518515.

[8] Jacobs PF. Rapid Prototyping \& Manufacturing: Fundamentals of StereoLithography: Society of Manufacturing Engineers, Technology \& Engineering; 1992.

[9] Melchels FPW, Feijen J, Grijpma DW. A review on stereolithography and its applications in biomedical engineering, Biomaterials 2010;31:6121-30. doi:10.1016/j.biomaterials.2010.04.050. 
[10] Salonitis K. Stereolithography. In: Compr. Mater. Process., Elsevier; 2014, p. 19-67. doi:10.1016/B978-0-08-096532-1.01001-3.

[11] Peyre P, Rouchausse Y, Defauchy D, Régnier G. Experimental and numerical analysis of the selective laser sintering (SLS) of PA12 and PEKK semi-crystalline polymers, J Mater Process Technol 2015;225:326-36. doi:10.1016/j.jmatprotec.2015.04.030.

[12] Gibson I, Shi D. Material properties and fabrication parameters in selective laser sintering process, Rapid Prototyp J 1997;3:129-136. doi:10.1108/13552549710191836.

[13] Bai J, Zhang B, Song J, Bi G, Wang P, Wei J. The effect of processing conditions on the mechanical properties of polyethylene produced by selective laser sintering, Polym Test 2016;52:89-93. doi:10.1016/j.polymertesting.2016.04.004.

[14] Childs THC, Berzins M, Ryder GR, Tontowi A. Selective laser sintering of an amorphous polymer - simulations and experiments, Proc Inst Mech Eng Part B J Eng Manuf 1999;213:333-349. doi:10.1243/0954405991516822.

[15] Crump SS, Apparatus and Method for Creating Three-dimensional Objects, Stratasys Incorporated, US patent 5121329 A, 1992.

[16] Singh R, Garg HK. Fused Deposition Modeling - A State of Art Review and Future Applications. In: Ref. Module Mater. Sci. Mater. Eng., Elsevier; 2016. doi:10.1016/B978-012-803581-8.04037-6.

[17] Gaub H. Customization of mass-produced parts by combining injection molding and additive manufacturing with Industry 4.0 technologies, Reinf Plast 2016;60:401-4. doi:10.1016/j.repl.2015.09.004.

[18] Casavola C, Cazzato A, Moramarco V, Pappalettere C. Orthotropic mechanical properties of fused deposition modelling parts described by classical laminate theory, Mater Des 2016;90:453-8. doi:10.1016/j.matdes.2015.11.009.

[19] Tymrak BM, Kreiger M, Pearce JM. Mechanical properties of components fabricated with open-source 3-D printers under realistic environmental conditions, Mater Des 2014;58:242-6. doi:10.1016/j.matdes.2014.02.038.

[20] Domingo-Espin M, Puigoriol-Forcada JM, Garcia-Granada AA, Llumà J, Borros S, Reyes G. Mechanical property characterization and simulation of fused deposition modeling Polycarbonate parts, Mater Des 2015;83:670-7. doi:10.1016/j.matdes.2015.06.074.

[21] Wu W, Geng P, Li G, Zhao D, Zhang H, Zhao J. Influence of Layer Thickness and Raster Angle on the Mechanical Properties of 3D-Printed PEEK and a Comparative Mechanical Study between PEEK and ABS, Materials 2015;8:5834-46. doi:10.3390/ma8095271. 
[22] Lanzotti A, Grasso M, Staiano G, Martorelli M. The impact of process parameters on mechanical properties of parts fabricated in PLA with an open-source 3-D printer, Rapid Prototyp J 2015;21:604-17. doi:10.1108/RPJ-09-2014-0135.

[23] Ulu E, Korkmaz E, Yay K, Burak Ozdoganlar O, Burak Kara L. Enhancing the Structural Performance of Additively Manufactured Objects Through Build Orientation Optimization, J Mech Des 2015;137:111410. doi:10.1115/1.4030998.

[24] Durgun I, Ertan R. Experimental investigation of FDM process for improvement of mechanical properties and production cost, Rapid Prototyp J 2014;20:228-235. doi:10.1108/RPJ-10-2012-0091.

[25] Rankouhi B, Javadpour S, Delfanian F, Letcher T. Failure Analysis and Mechanical Characterization of 3D Printed ABS With Respect to Layer Thickness and Orientation, J Fail Anal Prev 2016;16:467-81. doi:10.1007/s11668-016-0113-2.

[26] Anitha R, Arunachalam S, Radhakrishnan P. Critical parameters influencing the quality of prototypes in fused deposition modelling, J Mater Process Technol 2001;118:385-388. doi:10.1016/S0924-0136(01)00980-3.

[27] Rodríguez JF, Thomas JP, Renaud JE. Mechanical behavior of acrylonitrile butadiene styrene (ABS) fused deposition materials. Experimental investigation, Rapid Prototyp J 2001;7:148-158. doi:10.1108/13552540110395547.

[28] Lee BH, Abdullah J, Khan ZA. Optimization of rapid prototyping parameters for production of flexible ABS object, J Mater Process Technol 2005;169:54-61. doi:10.1016/j.jmatprotec.2005.02.259.

[29] Rodríguez JF, Thomas JP, Renaud JE. Design of Fused-Deposition ABS Components for Stiffness and Strength, J Mech Des 2003;125:545-551. doi:10.1115/1.1582499.

[30] Domingo-Espin M, Borros S, Agullo N, Garcia-Granada AA, Reyes G. influence of Building Parameters on the Dynamic Mechanical Properties of Polycarbonate Fused Deposition Modeling Parts, 3D Print Addit Manuf 2014;1:70-7. doi:10.1089/3dp.2013.0007.

[31] Ahn S, Montero M, Odell D, Roundy S, Wright PK. Anisotropic material properties of fused deposition modeling ABS, Rapid Prototyp J 2002;8:248-57. doi:10.1108/13552540210441166.

[32] Carneiro OS, Silva AF, Gomes R. Fused deposition modeling with polypropylene, Mater Des 2015;83:768-76. doi:10.1016/j.matdes.2015.06.053.

[33] Chacón JM, Caminero MA, García-Plaza E, Núñez PJ. Additive manufacturing of PLA structures using fused deposition modelling: Effect of process parameters on mechanical properties and their optimal selection, Mater Des 2017;124:143-57. doi:10.1016/j.matdes.2017.03.065. 
[34] Melenka GW, Cheung BKO, Schofield JS, Dawson MR, Carey JP. Evaluation and prediction of the tensile properties of continuous fiber-reinforced $3 \mathrm{D}$ printed structures, Compos Struct 2016;153:866-75. doi:10.1016/j.compstruct.2016.07.018.

[35] Vaezi M, Chua CK. Effects of layer thickness and binder saturation level parameters on 3D printing process, Int J Adv Manuf Technol 2011;53:275-84. doi:10.1007/s00170-0102821-1.

[36] Zhang P, Liu J, To AC. Role of anisotropic properties on topology optimization of additive manufactured load bearing structures, Scr Mater 2017;135:148-152. doi:10.1016/j.scriptamat.2016.10.021.

[37] Guessasma S, Belhabib S, Nouri H. Significance of pore percolation to drive anisotropic effects of 3D printed polymers revealed with X-ray $\mu$-tomography and finite element computation, Polymer 2015;81:29-36. doi:10.1016/j.polymer.2015.10.041

[38] Kim E, Shin YJ, Ahn SH. The effects of moisture and temperature on the mechanical properties of additive manufacturing components: fused deposition modeling, Rapid Prototyp J 2016;22:887-94. doi:10.1108/RPJ-08-2015-0095.

[39] Puebla K, Arcaute K, Quintana R, Wicker RB. Effects of environmental conditions, aging, and build orientations on the mechanical properties of ASTM type I specimens manufactured via stereolithography, Rapid Prototyp J 2012;18:374-88. doi:10.1108/13552541211250373.

[40] Guessasma S, Nouri H, Roger F. Microstructural and Mechanical Implications of Microscaled Assembly in Droplet-based Multi-Material Additive Manufacturing, Polymers 2017;9:372. doi:10.3390/polym9080372.

[41] ABS Terluran GP35. TECHNICAL DATA SHEET, http://www.ineosstyrolutionindia.com/INTERSHOP/web/WFS/Styrolution-IndiaSite/en_US/-/USD/ViewProduct-Start?SKU=300600120829, (n.d.).

[42] Rutkowski JV, Levin BC. Acrylonitrile-butadiene-styrene copolymers (ABS): Pyrolysis and combustion products and their toxicity a review of the literature, Fire Mater 1986; 10:93-105. doi:10.1002/fam.810100303.

[43] Torrado Perez AR, Roberson DA, Wicker RB. Fracture Surface Analysis of 3D-Printed Tensile Specimens of Novel ABS-Based Materials, J Fail Anal Prev 2014;14:343-53. doi:10.1007/s11668-014-9803-9.

[44] Bellehumeur C, Li L, Sun Q, Gu P. Modeling of Bond Formation Between Polymer Filaments in the Fused Deposition Modeling Process, J Manuf Process 2004;6:170-8. doi:10.1016/S1526-6125(04)70071-7.

[45] Sood AK, Ohdar RK, Mahapatra SS. Parametric appraisal of mechanical property of fused deposition modelling processed parts, Mater Des 2010;31:287-95. doi:10.1016/j.matdes.2009.06.016. 
